\title{
Examination of the Abstraction Process of Complex Number Knowledge
}

\author{
Merve Coban (Corresponding Author) \\ Necmettin Erbakan University, Konya, Turkey \\ E-mail: merve.math.09@gmail.com \\ Dilek Sezgin Memnun \\ Uludag University, Faculty of Education, Bursa, Turkey \\ E-mail: dilekmemnun@gmail.com
}

Emre Dinc

School of Education, University of Delaware

Newark, Delaware, United States

E-mail: edinc@udel.edu

Received: November 15, 2018 Accepted: January 4, 2019 Published: February 6, 2019

doi: 10.5296/ire.v7i1.12923

URL: https://doi.org/10.5296/ire.v7i1.12923

\begin{abstract}
The aim of this study was to examine the abstraction process of tenth grade students' complex number knowledge. A semi-structured interview was held with two students who were successful at mathematics and who voluntarily participated in the study. In this interview, the students faced three different research problems prepared by the researcher in order to reveal the students' knowledge formation processes. The students studied these research problems together. In the meantime, their cognitive processes related to recognizing, building-with, and constructing of discourses was analysed. The analyses indicated that both of the students recognized and built-with the preliminary knowledge necessary for them to construct the knowledge of complex numbers. Moreover, it was understood that one of these students recognized and build-with their previous knowledge of linear functions, coordinate systems, and parallel displacement. In conclusion, it could be said that this student constructed the knowledge of complex plane.
\end{abstract}


Keywords: Instructional activities and practices, Evaluation, Algebra and algebraic thinking

\section{Introduction}

Mathematical concepts are very abstract concepts and, for this reason, students have difficulty constructing and making permanent these concepts in their minds. Moreover, giving knowledge directly to students having difficulty comprehending something structurally abstract does not lead them to build but memorize that piece of knowledge. Thanks to abstraction, that is to say knowledge formation, knowledge is formed in the student's mind and learning automatically takes place. Mathematical abstraction provides opportunities for the construction of mathematical concepts, the achievement of transition between concepts and, most importantly, the achievement of not comprehension through memorization but conceptual comprehension (Can, 2011). For this reason, the theme of abstraction occupies an important place throughout our mathematical education.

\subsection{Background and Theoretical Framework}

Abstraction is a structural process and is the construction of mental structures from mathematical structures, and mathematical structures from mental structures. It is the process of detaching a characteristic or characteristics, which objects have in common from objects, and giving names to this characteristic or these characteristics. The abstraction process is not a directly observable state. It takes place in the form of the isolation of a concept from its specific characteristics and the direction of the process is from a set of contexts toward a concept (Dreyfus, 2007; Mitchelmore, 2002; Sierpinska 1994; Tall, 1988; Yilmaz, 2011).

There are different abstraction theories examining students' knowledge formation processes. The $\mathrm{RBC}+\mathrm{C}$ abstraction model is important in that it enables us to examine the abstraction process over the cognitive processes of recognizing, building-with, constructing and consolidation (Dreyfus, 2007; Herskhowitz, Schwarz, \& Dreyfus, 2001). Each of these actions are observable and the abstraction process can be recognized deeply through the observation of these (Altun \& Yilmaz, 2010). The formation of abstraction occurs by going through three stages: a need for a new structure, the formation of a new abstract entity, which in this process the actions of recognizing and using are structures existing as intermingled, and the consolidation of abstraction in a way to facilitate a person's recognizing action. Abstraction occurs only in a problem-solving process in which the student performs the action of formation by using a new method or strategy (Hershkowitz, Schwarz \& Dreyfus, 2001). While forming a piece of knowledge, an individual makes associations with previous subject topics in the stage of recognizing, uses this knowledge in problem-solving in the stage of building-with, sets up a new knowledge structure in the stage of constructing, and finally reinforces the knowledge formed in the stage of consolidation. For this reason, in this study, the $\mathrm{RBC}+\mathrm{C}$ abstraction model will be used as a tool in analysing tenth grade students' knowledge abstraction process.

Mathematics education enables students to develop creative thinking, starting from early ages. In education process the development of creative thinking is possible with a suitable educational teaching environment (Cenberci \& Yavuz, 2018). With mathematics education 
and learning-teaching activities included in this education process, students are expected to acquire the characteristics of reasonable and systematic thinking with the aim of analysing events, reasoning, associating, and generalizing. Thinking styles are very important in mathematics education where science and technology rapidly developing in this era (Ince, Cenberci \& Yavuz, 2018). Moreover, giving students characteristics of mathematical concepts, formulas, and theorems readily, without making any explanations, causes students to develop negative attitudes towards mathematics courses (Ozbellek \& Gulsen, 2003: 82). It was observed in the reviews made that there were a limited number of studies made on complex numbers in Turkey. Some of these studies (Celik \& Ozdemir, 2011; İpek, 2003; Keceli \& Turanl1, 2013; Ozdemir, 2006; Turanl1, Keceli \& Turker, 2007) examine misconceptions and mistakes surrounding complex numbers. Of these studies, as a result of the one made by Celik and Ozdemir (2011), it was observed that an large part of the students $(65 \%)$ failed to understand the topic of complex numbers, starting from the introduction to the topic of complex numbers and even the equation of $x^{2}+1=0$, which can be considered as the birth equation of complex numbers, and when the need for the set of complex numbers was most apparently observed. Moreover, about half of the students had problems related to the comparison of the set of real numbers with the set of complex numbers and the transition between these two sets. One of the misconceptions put forward in relation to complex numbers is the misconception of the $\sqrt{a} \cdot \sqrt{b}=\sqrt{a \cdot b}$ rule, which is valid for the set of real numbers is valid for the set of complex numbers as well (Schechter, 2006; Turanl1, Keceli \& Turker, 2007). Moreover, one of the misconceptions about this matter is in the determination of the real and imagined part of a complex number containing more than two terms and mistakes related to its demonstration. Among other misconceptions are the addition of all terms in the addition procedure of two complex numbers and the mistake of changing the sign of the second term when a complex number has a conjugate (Kecell \& Turanl1, 2013; Turanl, Keceli \& Turker, 2007). However, some of the studies made (Sakalli, 2011) make evaluations about the teaching of complex numbers. In the reviews made, no studies, which examine the learning process of the topic of complex numbers, were found in Turkey.

\subsection{The Aim of the Research}

This study aimed to examine whether the tenth grade students construct knowledge of complex numbers included in the learning domain of Numbers and Algebra with their own mental comprehension abilities and readiness via the $\mathrm{RBC}+\mathrm{C}$ abstraction model. With this aim, an answer was sought to the research problem: "How do tenth grade students construct the knowledge of complex numbers?"

In this study, starting from the need for sets of complex numbers, the students will be asked to construct the knowledge of complex numbers themselves by recognizing and building-with the sets, which they learned previously. In this context, the students will try to find the roots of a second-degree equation and, in cases when a real root cannot be found, it will make them recognize the need for a new set. 


\section{Methodology}

In this study, the students' knowledge formation processes in relation to complex numbers will be examined, rather than making a generalization about the students' thinking processes, they will be examined thoroughly and in detail. The relationships affecting these thinking processes will be explained in a certain systematic approach. Hence, in this study, with a limited number of participating students, a lot of data will be obtained. For this reason, in this study, the abstraction process was examined through interviews.

\subsection{Participants of the Study}

This study was carried out with two tenth grade students receiving education in a school in the province of Bursa. They had not previously studied the topic of complex numbers. These students were the tenth grade students who were eager to participate in this study and were reported by their mathematics teacher to be successful in math lessons. These students were given the nicknames of Burak and Ece. With the administration of the practice with two students at the same time, it was aimed to give them the opportunity to receive peer support and, in this way, make them talk about the topic and vocalize their thoughts. Hence, it became possible to see which mental processes they had undergone and how they constructed the knowledge.

\subsection{Data Collection}

Three different research problems were prepared with the aim of examining the participant tenth grade students' knowledge formation processes in relation to complex numbers. At this stage, the appropriateness of the problems was determined, expert opinions were taken too. Hence, the validity of the problems was achieved. Within the scope of the study, prior to the interview held in the fall semester of the 2014-2015 educational year, the participant students were told that the aim of the interview was to examine the process of reaching an answer, rather than reaching a correct or incorrect answer.

The semi-structured interview was held with two participant students simultaneously in the same environment. The practice was carried out in a classroom and recoded with a video camera placed where the students could see. Hence, the possibility of forgetting the environment in which the observation was made and the interview was held after a while was eliminated. At the same time, these recordings gave the researcher the opportunity to re-watch whenever she wanted to and to postpone her final decision about an appropriate approach until she was sure about what to emphasize. Hence, researchers can find rare and frequent instances by winding and rewinding the recording and, before making a quick decision about an event, they can change or correct their interpretations by watching previous or following parts (Toptas, 2008). The data of this study was obtained from the research problems enabling abstraction to take place within a process, revealing the students' mathematical thinking levels and knowledge formation processes. The problems had been prepared in a way to include a new structure and enable the consolidation of this structure and also from the students' attempts to solve these problems. Moreover, thanks to the worksheets 
given to the students, written information considered to make a contribution to the explanation of the students' knowledge formation processes was reached.

\subsection{Data Analysis}

The analysis and interpretation of the data were realized through the worksheets, including the answers given by the students to the research problem and the descriptive analysis - one of the types of qualitative data analyses - of the video recordings kept during the interviews.

The aim of descriptive analysis is to present obtained data in an organized and interpreted way. For this purpose, obtained data is described systematically and clearly (Yildirim \& Simsek, 2005: 224). At this stage, it is necessary to examine the data carefully several times and divide obtained information into meaningful sections (Kumbetoglu, 2005: 155). In this study, in the examination of the students' knowledge formation processes, the $\mathrm{RBC}+\mathrm{C}$ theory was used. Within this scope, the statements obtained in the knowledge formation process were organized systematically and were clearly analysed from a cognitive aspect. At this stage, dialogues and images recorded during the interview were turned into written texts. After that, a new framework was created by starting from the conceptual framework in the $\mathrm{RBC}+\mathrm{C}$ abstraction model and, according to this framework, it was determined under which themes the data would be organized and presented. In the examination of the knowledge formation processes, since the $\mathrm{RBC}+\mathrm{C}$ abstraction model was used as a tool, the themes determined for the analysis of the written interview texts were recognizing, building-with, constructing, and consolidation. By considering the dialectical structure of the process, these cognitive processes were observed and recorded together in the solution of the problem. Finally, in order to make sense of the findings previously described and presented in detail, explain the relationships between these findings, and draw some conclusions, interpretations were made based on the data.

The validity and reliability of this study were achieved via the questions used during the semi-structured interview, and the examination and evaluation of the interview and observation processes. In order to determine the appropriateness of the research question for the purpose of the study, the opinions of different experts working in the field were taken and the research question was revised in the direction of the suggestions made. Following the practice, the researchers evaluated the observation notes they took during both interviews and the internal validity of the long-lasting interaction achieved throughout the study was analysed using various data collection tools. The field experts' examinations and the external validity was achieved through the descriptive form of the interview. In the study, following the practice made for reliability, the voice recordings and observation notes were interpreted by two different researchers in terms of the "observability" of the cognitive processes and it was observed that the interpretations were consistent with one another and those of the researchers.

\section{Results}

Within the scope of this study, this practice was carried out with two successful tenth grade students participating in the study and lasted 29 minutes. 


\section{Macrothink}

The first research problem was composed of the following questions:

a. Find the solution set of " $x-3=0$ equation in the natural numbers.

b. Find the solution set of the $x+3=0$ equation in the natural numbers.

c. Find the solution set of the $x^{2}-1=0$ equation in the real numbers.

d. Find the solution set of the $x^{2}+1=0$ equation in the real numbers.

$\boldsymbol{e}$. Find the solution set of the $x^{2}-9=0$ equation in the real numbers.

$f$. Find the solution set of the $x^{2}+9=0$ equation in the real numbers.

g. Find the solution set of the $x^{2}+16=0$ equation in the real numbers.

$\boldsymbol{h}$. Find the solution set of the $x^{2}+25=0$ equation in the real numbers."

These questions were prepared with the aim of having the students anticipate the need for a new set in a set where the independent variables of an equation are described or in cases when the solution set is composed of an empty set and the fact that the sets where variables of an equation are described are insufficient to find a solution set. In this section, the students tried to answer the questions during a period of 15 minutes. Below are given some important interview transcripts from this part of the study.

B12: Hmm... Here, real numbers can be used in positive quadratic numbers such as $\mathrm{x}^{2}=1$ or $\mathrm{x}^{2}=9$... but I cannot benefit from real numbers in negative quadratic numbers such as $\mathrm{x}^{2}=-16$ or $\mathrm{x}^{2}=-9$.

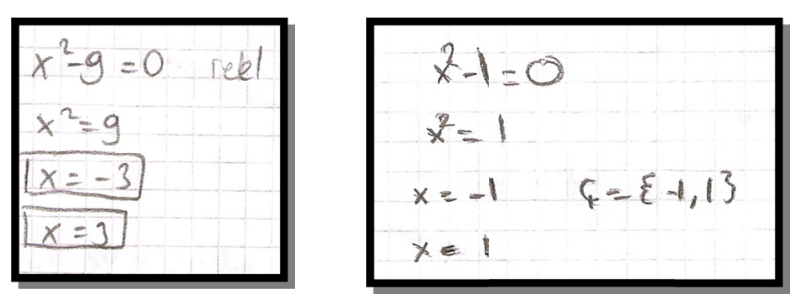

Figure 1. The students' solutions for the third and fifth questions in this research problem

The students' statements in this part of the study point to their knowing and using the knowledge of second-degree equations in the solution of the questions here.

E13: Yes, I could not state $x$ in the $x^{2}+1=0$ equation in the real numbers.

A14: Well, what are we supposed to do in this case?

B14: Let's expand the equations as far as we can... 


\section{Macrothink}

A15: What do you mean? Can you explain?

B16: I mean, firstly, I write $x^{2}=-16$ as it is. Then, I put both sides into square root...

E17: Hmm... Then, it will be the same for $x^{2}=-9 \ldots$

A18: How? Can you show me?

E19: I mean like this... Let's suppose I want to find the roots for the $x^{2}=-9$ equation in the same way...

B20: Yes, I think we can find the $x$ solutions in this way.

(Given below is the solution written by the students in the meantime.)
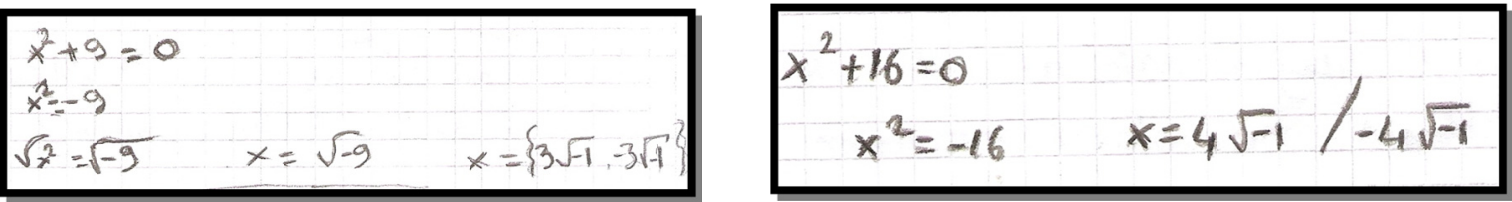

Figure 2. The solutions for the sixth and seventh questions in the first research problem

In this part of the interview, Burak and Ece shared what they thought out loud with each other. In the meantime, Burak's statement that "we can find $x$ solutions" makes us consider that this student anticipated that the solution was an empty set in the desired number set but there was need for a new set, accepting the found $x$ solutions as elements in the given research problem. This makes us consider that the students started to build background in order to create a new number set. Moreover, the students' statements in this part indicate that the students used the knowledge of second-degree equation in their solutions to the questionsi. Further, what the student wrote in Figure 2, and their statements in this part, again indicate that these students recognized and built-with the root numbers within the scope of the real numbers.

A21: Well, in this case, if you needed a number set, how could you describe it?

B22: Now, when this is the case... If I found a lot of equations of this kind, there would occur the same thing every time... I mean if it were $\sqrt{-36}$, again I would not change the $\sqrt{-1}$ statement... I mean this will remain the same ...

E23: Then, will the new set again include the numbers with $\sqrt{-1}$ ?

A24: If you wanted to give names to this number set, what name would you give it?

E25: I would call it "mysterious numbers"... For the -1 value never comes out of the root.

B26: I think I would call "consolatory numbers" as well... Let's give $\sqrt{-1}$ a nickname, too... For example, let it be " $a$ " of the consolatory numbers..." $a$ " of the consolatory numbers... 
E27: Hmm... it could be...

In this part of the interview, it was observed that Burak knew that the terms with $\sqrt{-1}$ included in the new set of numbers could not go out of the square root in the real numbers set but acknowledged the existence of the statements with $\sqrt{-1}$ in order to create a new set of numbers and called this new set of numbers "consolatory numbers". Moreover, Ece also stated that the value of (-1) could not come out of the root and, in her statement in E25 and E27, approved of Burak's statements. This indicates that these students recognized the insufficiency of the real numbers and, for this reason, makes us consider that these students constructed the set of complex numbers covering the real numbers; in other words, they constructed the knowledge of complex numbers.

In the second research problem, the students were asked to answer the problem prepared in the form of: "We expressed the elements of the number sets which we have learned up to now on the number line and the coordinate plane. Can we express the elements of the new set existing according to the new set, which we described on the axes? In your opinion, how can we do it?"

In this research problem, the students were expected to create the complex numbers, express them on the axes, and make a transition to the complex plane by setting up a relationship with the demonstration of the real numbers on the coordinate system. Therefore, in these problems, with the aim of determining whether these students would reach the complex plane, the students needed the skills of establishing associations and reasoning. In other words, these students were expected to create the complex plane, which was a new structure, by benefiting from their previous learning. That is to say, by relating with the coordinate plane where they demonstrated the real axes. After that, the students were expected to show the complex numbers on the created complex plane in a standard form, including the real and imaginary parts together, and this is important for the transition from complex numbers to the concept of the "complex plane". The students were expected to express these numbers, which they found and accepted as a new number set and called "consolatory numbers" on the axes.

These tenth grade students discussed the research problem included in this part of the study for about 5 minutes.

In this part of the study, the students read this research problem and then discussed if they would draw only one axis or two axes for the consolatory numbers. Some of the interview texts included in this part are given below.

B34: Seeing that they are the numbers composed of only $\sqrt{-1}$ statements, it is enough to draw only one axis.

E35: Hmm... Then let's draw it like a number line and place them one by one.

In this part of the interview, Burak's statement can be linked to the fact that the topic of second-degree equations included in the tenth grade curriculum had not been studied yet. It is considered that it might also have resulted from their not knowing the fact that in cases when 


\section{Macrothink Institute ${ }^{\mathrm{TM}}$}

the discriminant is below zero, the standard forms of the roots obtained when making root examinations include imaginary and real parts. In this context, it is natural that the students placed the complex numbers on a single axis.

The third research problem, with which the students were presented is as follows: "Well, if the roots of these equations were composed of not a single term, but a multi-term, for example, how could you demonstrate the elements of the equation with the roots of $(3+\sqrt{-16})$ and $(3-\sqrt{-16})$ or the those of the equation with the roots of $(4+\sqrt{-25})$ and $(4-\sqrt{-25})$ on the axes?"

With the designed research problem, the students were expected to make a transition to the real and imaginary axes. The students worked on this problem for a total of 9 minutes.

B47: Hmm... Now I understood. $(3+\sqrt{-16})$ I mean $(3+4 a) \ldots$ As if it were in $y=a x+b \ldots$

A48: How? Can you explain?

B49: I mean when it is $y=a x+b$, a shift is occurring on the $b y$-axis.

A50: Can you express it more clearly?

B51: I mean, in the statement of $3+4 a$, as if the value of $a$ were like the $x$-variable and it were $b$ in $3 \ldots$ I mean, as if it were $y=4 x+3 \ldots$ I mean, when I mark $4 a$ on the $x$-axis, it is like shifting $4 a$ in the statement of $3+4 a, 3$ units above on the $y$-axis ...

A52: Well, if you wanted to give names to these axes, what would you call?

(In the meantime, Ece listened to her friend's explanations silently.)

B53: I would call the values including statements with $\sqrt{-1}$ the axis with $a$ the $x$-axis and the $y$-axis the shift axis. (Ece did not make a comment or ask a question.)

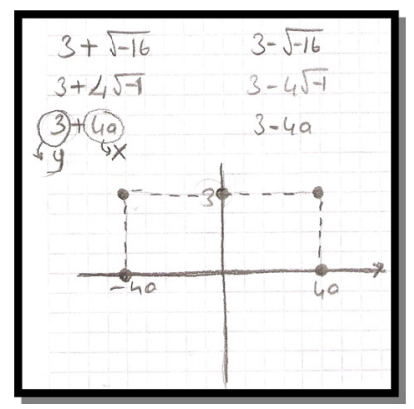

Figure 3. Graph drawn by burak for the third research problem

In this part of the interview, Burak thought of the complex number given in the standard form as a linear function. Again, in this process, it is notable that this student considered that the demonstrations of linear function graphs in the form of such a linear function as $y=a x+b$ on the analytical plane were achieved through shifting the $y=a x$ linear function as much as $b$ unit on $y$-axis $b$. This points to the fact that Burak recognized and built-with his background 
knowledge of linear functions, coordinate systems and shifting of linear functions in the solution of this problem. That this student named the real axis on the complex plane as the shifting axis makes us consider that this student constructed the knowledge of complex plane as a result of the relationship, which he set up with the coordinate axis. However, in this part, Ece remained silent and did not make any comment on Burak's explanations. For this reason, it cannot be stated that this student also constructed this piece of knowledge.

\section{Discussion and Conclusion}

In this study, the high school tenth grade students' complex number knowledge construction processes were examined through the $\mathrm{RBC}+\mathrm{C}$ abstraction model. As a result of the examinations made, it was observed that these participant students recognized and built-with the knowledge of second degree equations and root numbers from their background information, which was necessary for them to construct the knowledge of the complex numbers in the solution of the problems included in this study. Similarly, of these students, Burak, at the same time, recognized and built-with his background knowledge of linear functions, coordinate systems and shifting of linear functions to reach the knowledge of complex planes in the solution of this problem. He then named the real axis on the complex plane as the shifting axis and, as a result of the relationship he established with the coordinate system, constructed the knowledge of complex plane. Since she remained silent in the final part of this interview and did not make any comment on what Burak explained, we could not determine clearly whether Ece constructed this information or not. In order to understand if this student constructed the knowledge of complex numbers, there is a need for to put into practice a new research problem.

\section{References}

Altun, M., \& Yilmaz, A. (2010). High school students' processes of constructing and reinforcing piecewise function knowledge. Uludag University Faculty of Education Journal, XXIII(1), 311-337.

Can, M. (2011). Matematiksel soyutlama ve soyutlamanin indirgenmesi (Unpublished master thesis). Yildiz Technical University, İstanbul, Turkey.

Celik, A., \& Ozdemir, M. F. (2011). Determining the concepts errors with regard to complex numbers in secondary education. Buca Faculty of Education Journal, 29, 203-229.

Cenberci, S. I., \& Yavuz, A. (2018). The Correlation Between the Creative Thinking Tendency of Mathematics Teacher Candidates and Their Attitudes Towards Instructional Technologies and Material Design Lesson. World Journal of Educattion, 8(3), 95-106. https://doi.org/10.5430/wje.v8n3p95

Dreyfus, T. (2007). Processes of abstraction in context the nested epistemic actions model. Retrieved on November 13, 2014 from http://escalate.org.il/construction_knowledge/papers/ dreyfus.pdf 
Hershkowitz, R., Schwarz, B., \& Dreyfus, T. (2001). Abstraction in context: Epistemic actions. Journal for Research in Mathematics Education, 32(2), 195-222. https://doi.org/10.2307/749673

Ince, H., Cenberci, S., \& Yavuz, A. (2018). The Relationship Between the Attitudes of Mathematics Teacher Candidates Towards Scientific Research And Their Thinking Styles. Universal Journal of Educational Research, 6(7), 1467-1476. https://doi.org/10.13189/ujer.2018.060707

Ipek, A. S. (2003). Kompleks sayllarla ilgili kavramlarin anlasilmasinda gorsellestirme yaklasimi etkinliginin incelenmesi (Unpublished Doctoral Dissertation). Ataturk University, Erzurum, Turkey.

Keceli, V., \& Turanl1, N. (2013). Misconceptions and common errors in complex numbers. Hacettepe University Journal of Education Faculty, 28(1), 223-234.

Kumbetoglu, B. (2005). Sosyolojide ve antropolojide niteliksel yontem ve arastilrma. Ankara, Turkey: Baglam.

Mitchelmore, M. (2002). The role of abstraction and generalization in the development of mathematical knowledge. Paper presented at the Proceeding of the 9th East Asia Regional Conference on Mathematics Education and the Southeast Asian Conference on Mathematics Education (pp. 27-31), Singapore.

Ozbellek-Gulsen, S. (2003). Ilkogretim 6. ve 7. sinıf duzeyindeki aci konusunda karsilasilan kavram yanilgileri, eksik algilamalarin tespiti ve giderilme yontemleri (Unpublished Master Thesis). Dokuz Eylul University, Izmir, Turkey.

Ozdemir, M. F. (2006). Ortaogretimde kompleks sayllarla ilgili kavram yanilgilarinin belirlenmesi ve cozum onerileri (Unpublished Master Thesis). Dokuz Eylul University, İzmir, Turkey.

Sakalli, A. F. (2011). The influence of constructive 5E model about teaching complex numbers subject on students academic achievement and attitudes (Unpublished Master Thesis). Kahramanmaras Sutcu Imam University, Kahramanmaras, Turkey.

Schechter, E. (2006). The Most Common Errors In Undergraduate Mathematics. Retrieved on November 17, 2014 from www.math.vanderbilt.edu.

Sierpinska, A. (1994). Understandings in mathematics. London, England: Falmer.

Tall, D. (1988). The nature of advanced mathematical thinking. The Working Group for Advanced Mathematical Thinking for The Conference of the Physcology of Mathematics Education, Veszprem, Hungary.

Toptas, V. (2008). An examination of the teaching-learning process and teaching materials used in the instructon of geometry sub-learning fields in a first grade classroom. Ankara University Journal of Faculty of Educational Sciences, 41(1), 299-323. 


\section{Macrothink}

International Research in Education

ISSN 2327-5499

2019, Vol. 7, No. 1

Turanlı, N., Keceli, V., \& Turker, N. K. (2007). Ortaogretim ikinci sınıf öğrencilerinin karmasik sayilara yonelik tutumlari ile karmasik sayilar konusundaki kavram yanilgilari ve ortak hatalari. Balikesir University Journal of Science Institute, 9(2), 135-149.

Yildirim, A., \& Simsek, H. (2005). (Qualitative research methods in social sciences) Sosyal bilimlerde nitel araştırma yöntemleri (Fifth edition). Ankara, Turkey: Seckin.

Yilmaz, R. (2011). Matematiksel soyutlama ve genelleme sureclerinde gorsellestirme ve rol (Unpublished Doctoral Thesis). Gazi University, Ankara, Turkey.

\section{Copyright Disclaimer}

Copyright reserved by the authors.

This article is an open-access article distributed under the terms and conditions of the Creative Commons Attribution license (http://creativecommons.org/licenses/by/3.0/). 